\title{
Immunohistochemical and Genetic Analysis of Non- Small Cell and Small Cell Gallbladder Carcinoma and Their Precursor Lesions
}

Anil V. Parwani, M.D., Ph.D., Joseph Geradts, M.D., Eric Caspers, M.D., G. Johan Offerhaus, M.D., Charles J. Yeo, M.D., John L. Cameron, M.D., David S. Klimstra, M.D., Anirban Maitra, M.D., Ralph H. Hruban, M.D., Pedram Argani, M.D.

Departments of Pathology (AVP, AM, RHH, PA), Surgery (CJY, JLC), and Oncology (CJY, RHH), The Johns Hopkins Hospital, Baltimore, Maryland; Department of Pathology and Laboratory Medicine (JG), Roswell Park Cancer Institute, Buffalo, New York; The Academic Medical Center (EC, GJO), Amsterdam, The Netherlands; and Department of Pathology, Memorial Sloan-Kettering Cancer Center (DSK), New York

Gallbladder carcinomas can be highly lethal neoplasms. Relatively little is known about the genetic abnormalities that underlie these tumors, particularly with respect to their timing in neoplastic progression. The authors evaluated 5 noninvasive dysplasias and 33 invasive gallbladder carcinomas $(6$ small cell carcinomas, 27 non-small cell carcinomas, of which 16 were accompanied by an in situ carcinoma component) for expression of the protein products of the p16, p53, Dpc4, and pRB tumor suppressor genes by immunohistochemistry. Neoplasms were also evaluated for the presence of activating K-ras oncogene mutations. Seventy-five percent of non-small cell gallbladder carcinomas demonstrated loss of p16 expression, whereas $63 \%$ accumulated high levels of p53. Loss of Dpc4 and pRB expression was less frequent, seen in $19 \%$ and 4\% of the neoplasms, respectively. Thirty percent of neoplasms harbored activating K-ras mutations. In contrast, $100 \%$ of the small cell carcinomas of the gallbladder demonstrated inactivation of the pRB/ p16 pathway; $67 \%$ showed loss of $\mathrm{pRB}$ expression, and the other $33 \%$ lost p16 expression. Eighty-three percent of small cell carcinomas accumulated high levels of p53, whereas loss of Dpc4 expression and activating K-ras mutations were not found. Among 15 evaluable in situ components, 13 harbored the same alterations found in the invasive component.

Copyright ( $(2003$ by The United States and Canadian Academy of Pathology, Inc.

VOL. 16, NO. 4, P. 299, 2003 Printed in the U.S.A.

Date of acceptance: January 28, 2003.

Supported by the Margaret Lee Fund for Gallbladder and Bile Duct Cancer research at The Johns Hopkins Hospital.

Address reprint requests to: Pedram Argani, M.D., The Johns Hopkins Hospital, Surgical Pathology, Weinberg Building, Room 2242, $401 \mathrm{~N}$. Broadway, Baltimore, MD 21231-2410; fax: 410-955-0115; e-mail: pargani@jhmi.edu.

DOI: 10.1097/01.MP.0000062656.60581.AA
Inactivation of p16 and p53 occur in the majority of non-small cell gallbladder carcinomas. Dpc4 inactivation and K-ras mutations occur in a significant minority of cases. pRB loss is uncommon in nonsmall cell gallbladder carcinoma, but virtually all small cell carcinomas inactivate the $\mathrm{p} 16 / \mathrm{pRB}$ pathway, usually by retinoblastoma protein loss. It is noteworthy that all of these alterations occur at the level of carcinoma in situ.

KEY WORDS: Carcinoma, Gallbladder, Genetics, Immunohistochemistry, Tumor-suppressor gene. Mod Pathol 2003;16(4):299-308

Carcinoma of the gallbladder is a relatively uncommon, poorly understood, but highly lethal malignancy that tends to present at an advanced stage (1-3). There are approximately 5000 newly diagnosed cases per year in the United States, with a female predominance. The incidence of gallbladder carcinoma demonstrates marked geographic variation; for example, it is the single largest cause of cancer death for women in Chile but accounts for $<0.5 \%$ of cancers in women in the United States (1). Much of the geographic variation correlates with the tendency to form gallstones, a recognized risk factor in gallbladder carcinogenesis. Other risk factors include an abnormal junction of the choledochopancreatic ducts (AJCPD; in which the bile duct and pancreatic duct unite well above the sphincter of Oddi, promoting reflux of pancreatic juice into the bile duct), familial adenomatous polyposis, and ulcerative colitis $(1,4)$. Overall 5-year survival is $<5 \%$ (1).

The molecular pathogenesis of gallbladder carcinoma remains enigmatic. Loss of heterozygosity (LOH; 5-8) and cytogenetic (9) studies of non-small cell gallbladder carcinoma have identified several 
loci of recurrent genetic loss. These loci likely harbor tumor suppressor genes that are inactivated and include chromosome arms 17p, 5q, 9p, 13q, and 18q. Alterations in several specific tumor suppressor genes that map to these loci have been identified (i.e., $p 53$ at $17 \mathrm{p} 13, p 16$ at $9 \mathrm{p} 21, R B$ at $13 \mathrm{q}$ ), but the data remain cloudy to date as differing studies have yielded differing results (5, 7, 8, 10-18). Some of the variation in results of immunohistochemical studies may be due to use of different techniques and cutoff points for positivity in different studies. The loci on $18 \mathrm{q}$ involved in gallbladder carcinoma have not been identified, with the $D C C$ and DPC4 genes being prime candidates. Finally, mutational activation of the K-ras gene has been demonstrated in $5-59 \%$ of cases $(7,14-18)$, with suggestions that this frequency may be increased in Japanese patients, particularly those with AJCPD. Small cell carcinomas of the gallbladder have been studied even less frequently (19).

In the present study, we analyzed our large series of resected non-small cell and small cell gallbladder carcinomas for Dpc4, pRB, p16, and p53 protein expression and for K-ras gene mutation.

\section{METHODS}

\section{Case Selection}

This study was approved by the Johns Hopkins Institutional Review Board. The computerized files of the Surgical Pathology Division of the Department of Pathology of The Johns Hopkins Hospital were searched over the years 1985-2000 for cases coded as "gallbladder" and "carcinoma." Cases were selected for study on the basis of availability of a paraffin-embedded, formalin-fixed tissue block. An additional case (Case 31) was obtained from Memorial Sloan-Kettering Cancer Center. For each case, a representative formalin-fixed, paraffinembedded tissue block containing carcinoma and normal tissue was chosen for labeling. For cases in which an in situ carcinoma component was noted, a block containing this component was specifically chosen for study.

\section{Cases}

We identified five cases of gallbladder dysplasia or carcinoma in situ unassociated with invasive carcinoma (Table 1) and identified 33 cases of invasive gallbladder carcinoma for which blocks were available. Patient ages ranged from 37 to 86 years (mean age $=62.8 \mathrm{y}$; median $=63.5 \mathrm{y}$ ), and the male-female ratio was 13:25. Twenty-one of 34 evaluable gallbladders harbored gallstones.

Two of the pure dysplasia cases were low grade, whereas three were high grade or carcinoma in situ. Of the invasive carcinomas, 16 were associated with an in situ component; of these, the in situ component had a flat component in 10 and was purely papillary in 6 .

Twenty-seven of the invasive carcinomas of the gallbladder were non-small cell carcinomas (Cases 1-27); these included 21 adenocarcinomas, 5 adenosquamous carcinomas (defined as showing variable mixture of malignant squamous and glandular components; 1 ), and 1 purely squamous carcinoma. Of these 27 neoplasms, the primary tumor was evaluated in 24 , and a metastasis was the only tissue available in 3 . Of these 24 primary tumors, 15 were moderately differentiated (defined as $40-94 \%$ of the tumor forming glands; 1 ), and 9 were poorly differentiated (defined as 5-39\% of the tumor forming glands; 1). Six other neoplasms contained a small cell (high-grade neuroendocrine) carcinoma component (Cases 28-33). Two of these six were pure small cell carcinomas (Cases 29, 30), whereas one was predominantly small cell carcinoma with focal squamous differentiation (Case 31). One tumor was associated with flat carcinoma in situ (Case 28), whereas two other invasive carcinomas had both small cell carcinoma and adenocarcinoma components along with papillary adenocarcinoma in situ (Cases 32, 33).

Several patients' tumors were associated with unusual clinical presentations or pathologic findings. One patient's gallbladder carcinoma arose within a septate gallbladder (Case 8). Another patient (Case 20) had concurrent colorectal adenocarcinoma and gallbladder carcinoma, whereas another patient's gallbladder carcinoma extended into the extrahepatic bile ducts, which harbored a carcinoid tumor (Case 13).

Patients tended to present at advanced stage. Using AJCC criteria (20), 29 of 30 patients' primary tumors presented at Stage 3 or above. At least 23 of 30 primary tumor resections were associated with

TABLE 1. Clinical and Molecular Features of Five Patients with Pure Dysplasia or Carcinoma In Situ

\begin{tabular}{cccccccc}
\hline Case Number & Age & Sex & Stone & p53 & Dpc4 & p16 & KRB \\
\hline 1 (LGD) & 39 & M & Yes & NL & NL & NL & NL \\
2 (LGD) & 37 & F & Yes & NL & NL & NL & NL \\
3 (CIS) & 71 & M & No & OE & NL & LOSS & NL \\
4 (CIS) & 63 & F & Yes & OE & NL & LOSS & MUT D (Val) \\
5 (CIS) & 57 & F & Yes & OE & NL & LOSS \\
\hline
\end{tabular}

$\mathrm{NL}=$ normal pattern (intact labeling for p16, Dpc4, and pRB, less than $30 \%$ expression of p53, wild type K-ras); OE = overexpression; LOSS = loss of expression; LGD = low-grade dysplasia; CIS = carcinoma in situ; MUT = K-ras mutation; Stone = gallstone present in specimen. 
positive surgical margins microscopically, indicating incomplete excision of the neoplasm.

\section{Immunohistochemistry for p53 and Dpc4}

Unstained $4-\mu \mathrm{m}$ sections were cut from the selected paraffin block and deparaffinized by routine techniques. The slides were steamed for 20 minutes in sodium citrate buffer (diluted to $1 \times$ from $10 \times$ heat-induced epitope retrieval buffer; Ventana-Bio Tek solutions, Tucson, AZ). After cooling for $5 \mathrm{~min}-$ utes, the slides were labeled for 40 minutes at room temperature with either a 1:100 dilution of a monoclonal antibody to Dpc4 (clone B8, Santa Cruz Biotechnology, Santa Cruz, CA) or a 1:250 dilution of a monoclonal antibody to p53 (clone DO-7, DAKO, Carpinteria, CA) using the Bio Tek 1000 automated stainer (Ventana). Labeling was detected by adding biotinylated secondary antibodies, avidin-biotin complex, and 3, 3'-diaminobenzidine. Sections were then counterstained with hematoxylin. Dpc4 and p53 immunolabeling were evaluated jointly by two authors (AVP, PA) using a multiobserver microscope, with agreement on all cases. For p53 labeling, a percentage of positive nuclei was determined. Carcinomas were divided into two groups: normal $(<30 \%$ nuclear labeling) and positive for high-level accumulation of p53 protein $(>30 \%$ nuclear labeling). The labeling cutoff was chosen based on previous studies that have demonstrated that this cutoff point correlates best with the status of the $p 53$ gene in colorectal carcinomas (21). For Dpc4 labeling, any area of uniform cytoplasmic labeling and focal nuclear labeling was considered positive. In statistical analysis, any carcinoma showing even focal nuclear and cytoplasmic labeling was considered positive (expressor), whereas carcinomas demonstrating no expression in a background of intact expression by non-neoplastic cells (desmoplastic stroma, normal peribiliary glands, etc., which served as internal controls) were considered negative (nonexpressors). The rationale for considering carcinomas that labeled only focally as positives is based on the study of Wilentz et al. (22), which found that pancreatic tumors with this focal staining pattern proved to have an intact DPC4 gene.

\section{Immunohistochemistry for $\mathrm{p} 16, \mathrm{pRB}$}

Immunohistochemistry for $\mathrm{p} 16$ and $\mathrm{pRB}$ was performed in the laboratory of one of the authors (JG) and interpreted by three of the authors (AVP, PA, and JG). Mouse monoclonal anti-RB antibody 3C8 was purchased from QED (San Diego, CA), and mouse monoclonal anti-p16 antibody 16P07 was obtained from LabVision/NeoMarkers (Fremont, CA). Nonspecific mouse IgG was used as a negative antibody control. Standard ABC peroxidase assays were performed as described in detail elsewhere (22-26). For detection of pRB, deparaffinized sections were incubated with anti-RB antibody 3C8 at $2 \mu \mathrm{g} / \mathrm{mL}$ for 2 hours, after an antigen retrieval step in $0.01 \mathrm{M}$ citrate buffer $\left(95-100^{\circ} \mathrm{C}\right)$. For detection of p16, sections were incubated with the anti-p16 monoclonal antibody $16 \mathrm{P} 07$ at $1 \mu \mathrm{g} / \mathrm{mL}$ at $4^{\circ} \mathrm{C}$ overnight, after antigen retrieval in $0.1 \mathrm{~m}$ EDTA pH $8.0\left(20 \mathrm{~min}\right.$ at $\left.95-100^{\circ} \mathrm{C}\right)$. The detection reactions for both markers used the Vectastain Elite ABC kit using conditions recommended by the manufacturer. Diaminobenzidine with hematoxylin counterstain was used for color development. Negative controls were labeled under identical conditions. The following external positive controls were used: normal colonic mucosa for pRB and p16 and a p16-positive lung cancer xenograft for p16. In addition, non-neoplastic stromal cells served as internal positive controls for $\mathrm{pRB}$ and p16 in every tumor section.

Each case was scored for pRB and p16 reactivity using previously published criteria (19, 23-26). Briefly, sections were examined for evidence of nuclear labeling above any cytoplasmic background; cytoplasmic labeling itself was disregarded. If there was nuclear labeling in a diffuse or mosaic distribution throughout the lesion, it was considered "positive" (normal) for the respective protein. If all of the neoplastic nuclei failed to label whereas admixed non-neoplastic cells reacted positively, the lesion was scored as "negative" (abnormal). Cases were scored initially by one author (JO), and scoring was subsequently reviewed by two authors (AVP, PA) using a multiobserver microscope with agreement on all cases.

\section{K-ras Gene Codon 12 Analysis}

For the K-ras gene analysis, tumor was microdissected from unstained paraffin-embedded section slides to ensure $\geq 50 \%$ neoplastic cells in the sample. K-ras codon 12 analysis was performed with allele-specific oligonucleotide (ASO) hybridization method, as described elsewhere (27). DNA was isolated from microdissected tumor tissue by overnight incubation at $56^{\circ} \mathrm{C}$ in proteinase $\mathrm{K}$ solution, followed by inactivation of proteinase $\mathrm{K}$ at $95^{\circ} \mathrm{C}$ for 10 minutes. DNA was amplified by PCR using K-ras codon 12 specific primers (27). PCR products were then digested with $M v a$ I, which only recognizes wild-type K-ras codon 12. Subsequently, a secondround PCR was performed on both the digested and undigested first-round PCR products. Cell suspensions with mutant-wild-type ratios of 1:100 and 1:1000 were used as positive controls in every PCR procedure. The cell suspensions were made of the human colon cancer cell line SW 480 with a ho- 
mozygous GGT to GTT mutation at codon 12 of $\mathrm{K}$-ras and the human colon cancer cell line HT 29 with wild type $\mathrm{K}$-ras. Water was used as a negative control, and placental DNA was used as a control for nonspecific hybridization. After denaturation, the undigested and digested (mutant-enriched) PCR products were spotted onto a nylon membrane and hybridized to each of the K-ras codon 12 mutation-specific oligodeoxynucleotides. Final stringency washes were carried out at $63^{\circ} \mathrm{C}$, followed by autoradiography. K-ras codon 12 mutational analysis was performed twice, in independent experiments.

In all cases, K-ras codon 12 mutations identified by ASO hybridization were confirmed by direct fluorescent sequencing using the dideoxy chain termination method (27). Mutant-enriched PCR products (second-round PCR products of ASO-test) were purified using the Qiaquick PCR purification kit (Qiagen Inc.). DNA was sequenced with the DNA sequencing kit, BigDye-Terminator Cycle sequencing Ready Reaction (Applied Biosystems, Warrington, United Kingdom). The reaction products were analyzed on an ABI Prism 3100 Genetic Analyser (Hitachi, Applied Biosystems). Selected wildtype cases were also sequenced.

\section{RESULTS}

Pure Dysplasias $(n=5)$

Neither of the two low-grade dysplasias demonstrated abnormal expression of p53, Dpc4, and p16 or pRB protein, and neither contained a K-ras gene mutation. In contrast, all three flat carcinoma in situ lesions demonstrated accumulation of p53 protein at high levels and demonstrated loss of p16 expression. pRB expression was intact and diffuse in these three cases, and Dpc4 was detectable in all three (Fig. 1). One of the three carcinoma in situ lesions harbored a K-ras mutation, involving conversion to valine (Table 1).

\section{Invasive Non-Small Cell Carcinomas $(n=27)$}

This group included 14 pure invasive non-small cell carcinomas and 13 invasive non-small cell carcinomas associated with an in situ carcinoma component. Loss of p16 expression and abnormal accumulation of p53 were the most common abnormalities noted in this group. Eighteen (75\%) of 24 evaluable tumors demonstrated loss of p16 expression. This included 10 of 12 carcinomas unassociated with an in situ component and 8 of 12
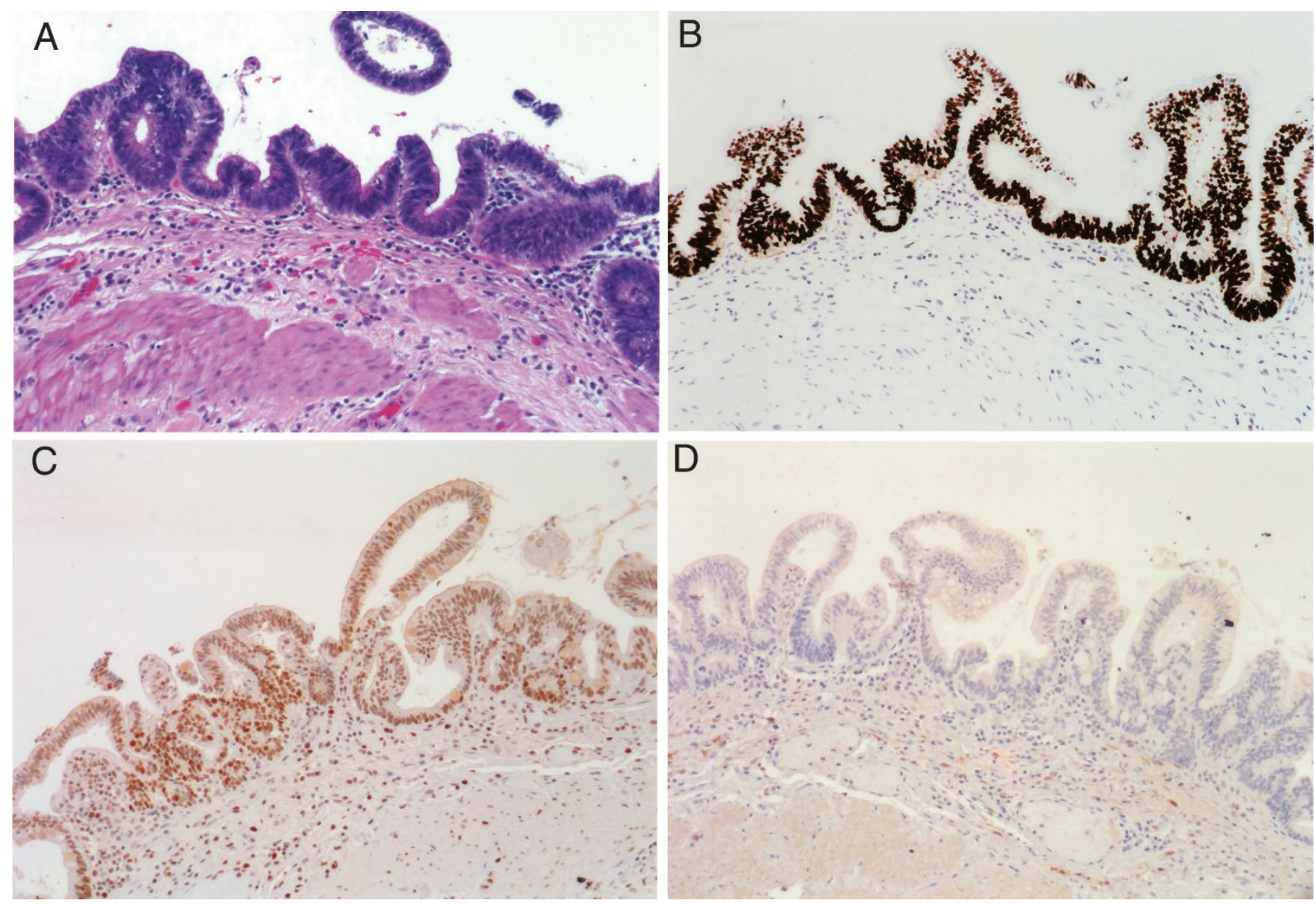

FIGURE 1. Flat carcinoma in situ (A) demonstrating p53 overexpression (B); intact, diffuse pRB expression (C); and loss of p16 expression (D). Note the intact patchy labeling of stromal and endothelial cells for p16. 
carcinomas associated with an in situ component. The six p16-positive tumors generally displayed a weak to moderate nuclear immunoreactivity in $<50 \%$ of cells in a mosaic pattern. Of note, in the case (Case 13) with concurrent gallbladder carcinoma and bile duct carcinoid tumor, p16 expression was intact in the carcinoid tumor but was lost in the poorly differentiated gallbladder carcinoma.

Seventeen of 27 carcinomas (63\%) accumulated p53 at high levels; this included 8 of 14 pure invasive carcinomas and 9 of 13 invasive carcinomas associated with an in situ component. Five of 27 invasive carcinomas (19\%) demonstrated loss of Dpc4 expression, including 3 of 14 pure invasive carcinomas and 2 of 13 invasive carcinomas associated with carcinoma in situ. Of note, Dpc4 expression was intact in the in situ and invasive carcinoma of the gallbladder but absent in the invasive colorectal carcinoma that were concurrently resected (Case 20), supporting the clinical and morphologic impression that these were independent primary neoplasms. Only 1 of 27 non-small cell carcinomas (4\%) showed loss of pRB expression; in this tumor the in situ component also demonstrated loss of $\mathrm{pRB}$ expression. Most tumors with intact $\mathrm{pRB}$ expression demonstrated extensive la- beling for $\mathrm{pRB}$, particularly those demonstrating loss of p16 expression (Fig. 2).

$\mathrm{K}$-ras gene mutations were identified in 8 of 27 invasive non-small cell carcinomas $(30 \%)$. Of the eight invasive adenocarcinomas harboring a $\mathrm{K}$-ras gene mutation, six were primary tumors and two were metastases. Five mutations involved conversion to aspartate, and three, to serine.

There were no significant differences in results for any tested marker among cases classified as moderately versus poorly differentiated.

\section{In Situ Carcinoma Components Associated with Invasive Non-Small Cell Carcinoma $(n=13)$}

There was a remarkable concordance between the immunohistochemical labeling of the in situ and the invasive non-small cell carcinoma components for p16, pRB, p53, and Dpc4 in the above cases. We identified p16 loss in 7 of 11 (64\%) evaluable in situ components; the invasive carcinomas corresponding to all of these tumors had shown p16 loss. We identified accumulation of p53 at high levels in 10 of 13 in situ lesions (77\%) associated with invasive carcinoma; this included all 9 cases in which the invasive component accumulated p53 at
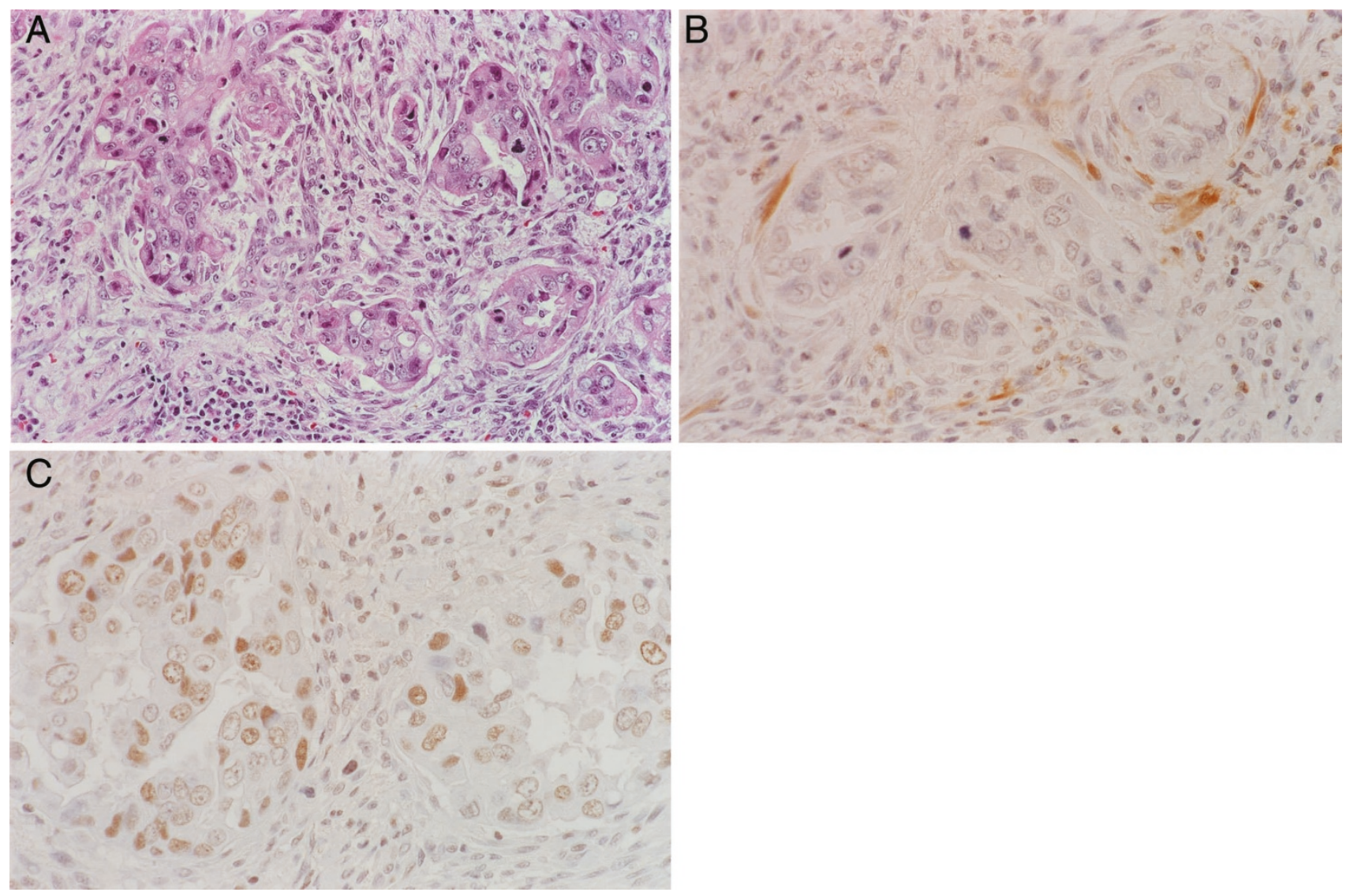

FIGURE 2. Infiltrating non-small cell carcinoma (A) demonstrating loss of p16 expression (B) and intact, diffuse pRB expression (C). Note the intact labeling of endothelial cells in Figure 2B. 
high levels. There was one case with discordant findings: in this case, the papillary in situ carcinoma component demonstrated high levels of p53, whereas the invasive component showed no p53 expression. We identified loss of Dpc4 expression in both of the in situ lesions associated with invasive carcinomas that showed loss of Dpc4 expression (2 of 13 in situ lesions overall, 15\%; Fig. 3), whereas we found loss of pRB expression in the in situ component of the one invasive carcinoma that showed loss of pRB ( 1 of 13 cases overall, $8 \%$ ).

\section{Invasive Small Cell Carcinomas $(n=6)$}

Accumulation of p53 at abnormally high levels was the most common abnormality noted, identified in five of six invasive small cell carcinomas. All six small cell carcinomas demonstrated evidence of inactivation of the $\mathrm{pRB} / \mathrm{p} 16$ pathway. In contrast to non-small cell carcinomas, loss of $\mathrm{pRB}$ expression more common in this tumor type, identified in four of six cases $(67 \%)$, whereas the other two small cell carcinomas with intact pRB expression demonstrated loss of p16 expression (Fig. 4). Dpc4 protein expression was intact in all six tumors, whereas $\mathrm{K}$-ras gene mutations were not identified in any of the three tumors evaluated.

\section{Non-Small Cell Components Associated with Small Cell Carcinomas $(n=3)$}

In two of three cases, the results were concordant. The flat carcinoma in situ associated with one small cell carcinoma and the papillary in situ and invasive adenocarcinoma associated with another each demonstrated p53 accumulation at high levels and p16 loss like their small cell components. In the other case, only the small cell carcinoma component demonstrated loss of p16 expression; the papillary in situ carcinoma and invasive carcinoma with which it was associated expressed p16.

The results of immunohistochemical assays are summarized in Table 2.

\section{DISCUSSION}

We studied a large series of resected gallbladder carcinomas for expression of the protein products
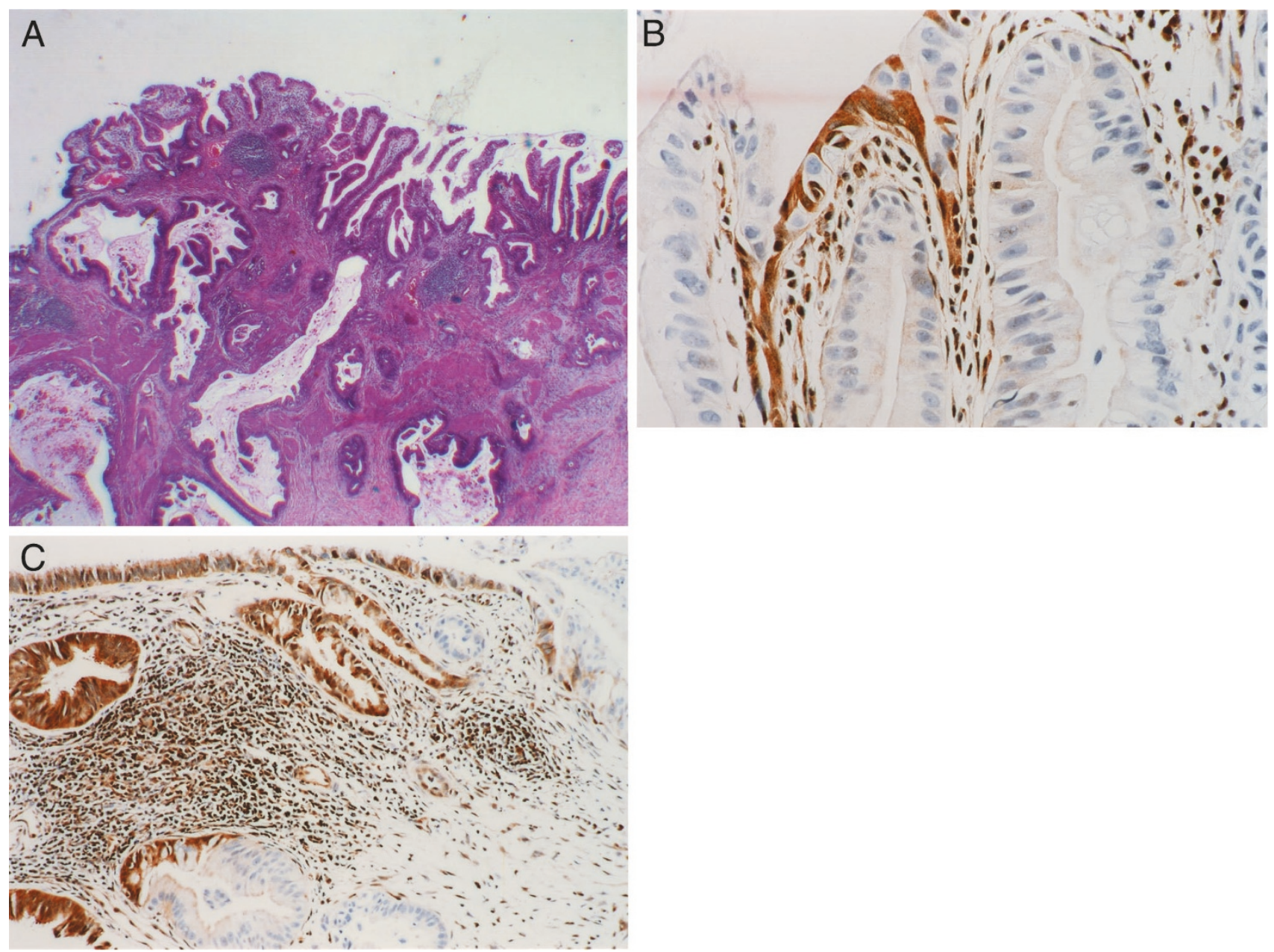

FIGURE 3. Papillary in situ and infiltrating carcinoma (A) demonstrating loss of Dpc4 expression in the in situ component (B) and in the invasive component (C). Note the intact labeling of normal stroma and benign gallbladder epithelium (Fig. 3C). 

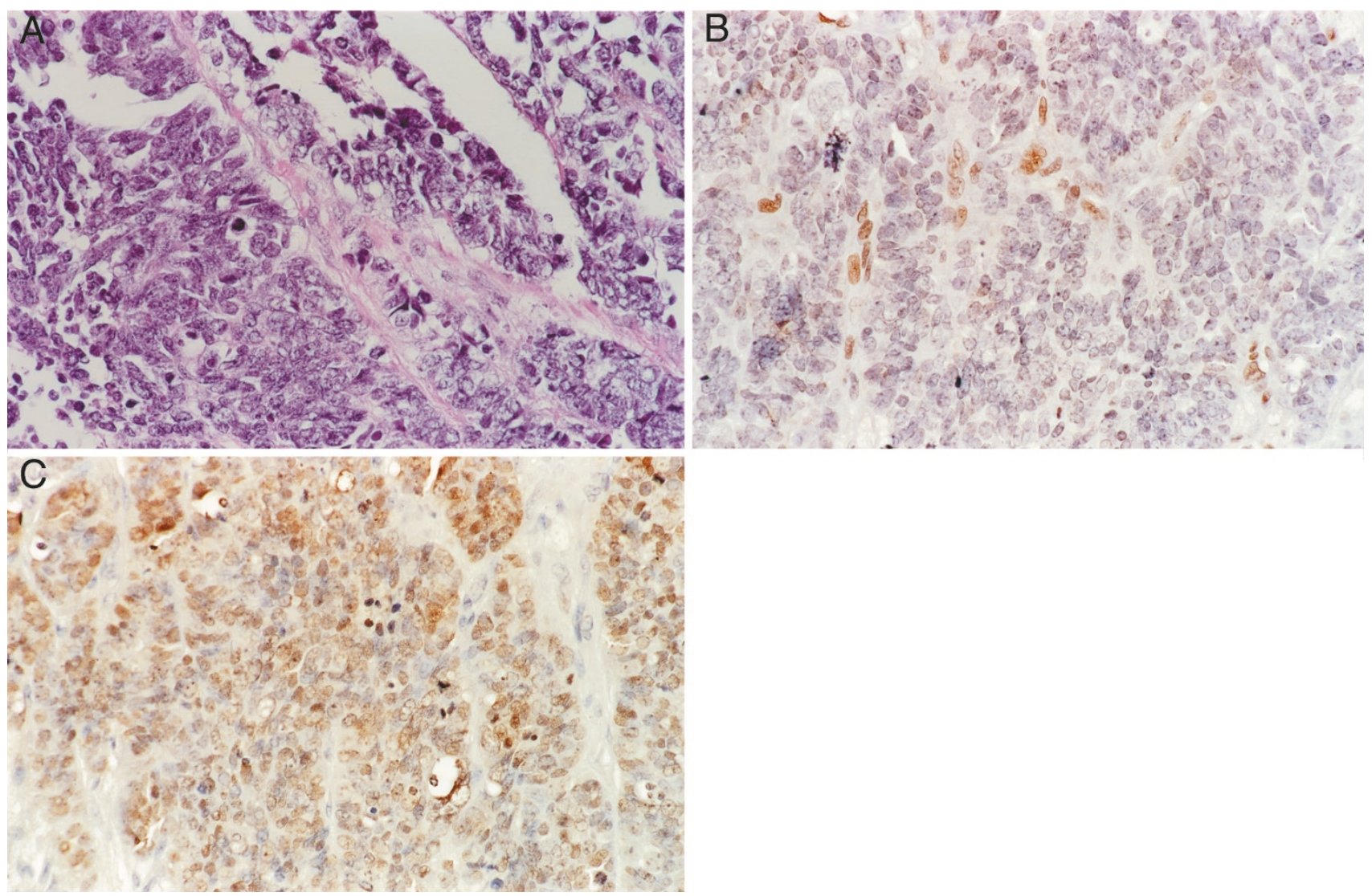

FIGURE 4. Small cell carcinoma (A) demonstrating loss of pRB expression (B) and intact, diffuse p16 expression (C). Note the intact labeling of endothelial cells for pRB in Figure 4B.

TABLE 2. Immunolabeling and K-ras Mutation Analysis: Summary

Invasive Carcinoma Cases

\begin{tabular}{|c|c|c|c|c|c|c|}
\hline & \multicolumn{2}{|c|}{ Dysplasia Only Cases } & \multicolumn{2}{|c|}{$\begin{array}{l}\text { In Situ Component of } \\
\text { Non-Small Cell Carcinomas }\end{array}$} & \multicolumn{2}{|c|}{ Invasive Component } \\
\hline & $\begin{array}{l}\text { Low } \\
\text { Grade }\end{array}$ & CIS & Flat & Papillary & $\begin{array}{l}\text { Non-Small Cell } \\
\text { Carcinoma }\end{array}$ & $\begin{array}{r}\text { Small Cell } \\
\text { Carcinoma }\end{array}$ \\
\hline p53 & $0 / 2$ & $3 / 3$ & $7 / 9$ & $3 / 4$ & $17 / 27(63 \%)$ & $5 / 6(83 \%)$ \\
\hline p16 & $0 / 2$ & $3 / 3$ & $6 / 8$ & $1 / 3$ & 18/24 (75\%) & $2 / 5(40 \%)$ \\
\hline pRB & $0 / 2$ & $0 / 3$ & $1 / 9$ & $0 / 4$ & $1 / 27(4 \%)$ & $4 / 6(67 \%)$ \\
\hline Dpc4 & $0 / 2$ & $0 / 3$ & $1 / 9$ & $1 / 4$ & $5 / 27$ (19\%) & $0 / 6(0 \%)$ \\
\hline K-ras & $0 / 2$ & $1 / 3$ & ND & ND & $8 / 27$ (30\%) & $0 / 3(0 \%)$ \\
\hline
\end{tabular}

$\mathrm{ND}=$ not determined.

* The data are expressed as the number of abnormal results/number of normal and abnormal results. These data do not include the non-small cell carcinoma components associated with the small cell carcinomas.

of the $p 16, D P C 4, R B$, and $p 53$ tumor suppressor genes and for mutation of the K-ras oncogene.

Our immunohistochemical results for p53 generally parallel those previously reported in the literature. A number of prior studies have shown that accumulation of p53 at high levels is frequent in invasive non-small cell carcinomas of the gallbladder and occurs at the level of carcinoma in situ (7, $10,11)$. Although most of these older studies have used primary antibodies other than the D0-7 clone (which is currently used by most laboratories), several have shown good correlation of p53 expression with $p 53$ gene mutation (10) and LOH at $17 p$ (7).
Our study is slightly different from those previously published in that we show a slightly higher frequency of high-level accumulation of p53 in in situ carcinoma than in invasive carcinomas. In contrast, most previous studies have shown progressive overexpression of p53 as dysplastic lesions progress to invasion $(5,7)$. Possible reasons for this difference could include variability in the antibody clone or immunohistochemical technique used, as well as criteria for distinction of low-grade dysplasia from carcinoma in situ. For example, it is possible that some of the lesions we designated low-grade dysplasia might be termed carcinoma in situ by others, 
which would reduce the frequency of p53 alterations somewhat. Nonetheless, because of the concordance between in situ and invasive carcinoma, our results suggest the possibility that gallbladder carcinomas may arise via two pathways, with those arising from flat carcinoma in situ overexpressing p53 and with those that do not being less likely to overexpress p53. The high frequency of p53 overexpression that we observed in small cell carcinomas of the gallbladder (83\%) is similar to that reported elsewhere (19).

To our knowledge, this is the first study to assess Dpc4 protein expression in non-small cell gallbladder carcinomas. The $18 \%$ frequency of loss of protein expression that we observed in non-small cell carcinomas is concordant with results from our previous studies of biliary tract carcinomas. Previously, we showed that loss of Dpc4 expression is as frequent in distal (intrapancreatic) bile duct carcinomas (55\%) as it is in pancreatic adenocarcinoma. In contrast, the frequency of Dpc4 loss was lower (overall, 15\%) in more proximal (perihilar and intrahepatic) bile duct carcinomas (28). Interestingly, we observed loss of Dpc4 protein in a similar percentage of in situ gallbladder carcinomas associated with invasive carcinomas (2 of 13 , or $15 \%$ ), suggesting that DPC4 inactivation occurs early in these lesions. The $18 \%$ frequency of Dpc4 protein loss in these tumors may account for a subset of the approximately $30 \%$ frequency of $\operatorname{LOH}(5,7)$ that has been reported at chromosome $18 \mathrm{q}$ in prior allelotyping studies of gallbladder carcinomas.

The significant role of $p 16$ alterations in the pathogenesis of gallbladder carcinomas has emerged in the recent literature. Although studies have shown a rate of mutation that ranges from 30.7 (13) to $80 \%$ (12), $\mathrm{LOH}$ at the p16 locus on chromosome $9 \mathrm{p}$ has been reported to range between 0 and $68 \%(7,8,12)$. To our knowledge, only two other studies have evaluated p16 protein immunolabeling in gallbladder carcinomas. Shi et al. (29) have recently shown loss of p16 expression in $75.7 \%$ of gallbladder carcinomas, whereas Kim et al. (13) showed loss of labeling in only $23 \%$. Our study is concordant with the results of Shi et al. (29) in that we saw frequent loss of p16 protein expression $(69 \%)$. It is interesting that the two adenocarcinomas associated with small cell carcinomas in this study maintained p16 expression, suggesting that they are biologically different from pure adenocarcinomas.

We found pRB loss to be infrequent in invasive non-small cell gallbladder carcinomas; in fact, most tumors expressed pRB diffusely. Diffuse pRB expression in these tumors likely reflects the sequelae of p16 inactivation, because p16 negatively regulates cellular levels of RB (30). In fact, inverse relationship of p16 and pRB has been demonstrated in several malignancies including bladder carcinomas, lung carcinomas, pancreatic carcinomas, and gliomas (30-32), and, most recently, gallbladder carcinomas (29). In our series, the inverse relationship was also apparent; no invasive carcinoma demonstrated loss of both p16 and pRB, whereas an inverse relationship (loss of p16 or Rb, but not both) was evident in 25 of 30 tumors. One would not expect inactivation of both of these tumor suppressor genes within the same tumor, because they each function in the same growth-regulatory pathway, and therefore there would be no selective pressure to inactivate both.

In contrast, we found that pRB loss was common (4 of 6 cases) in the small cell carcinomas available for study. Although pRB expression has, to our knowledge, never been evaluated in small cell carcinoma of the gallbladder before, pRB loss is common in pulmonary small cell carcinomas (33) and has been reported in small cell carcinomas in extrapulmonary sites $(34,35)$. Hence, gallbladder carcinomas appear to fit the paradigm that small cell (high grade) neuroendocrine carcinomas of any site are consistently characterized by loss of pRB expression. It is noteworthy that the two cases that retained $\mathrm{pRB}$ showed loss of $\mathrm{p} 16$, indicating that all small cell carcinomas of the gallbladder target the p16/pRB pathway.

The role of K-ras gene mutation in gallbladder carcinomas is not clear from the literature. Several groups have considered K-ras mutations to be "rare and late events" (7) in gallbladder carcinomas. Wistuba et al. (36) found K-ras gene mutations in only 1 of 21 gallbladder carcinomas, and the mutation was confined to the poorly differentiated area of this tumor. This same group found a higher frequency of K-ras gene mutation (25\%) in gallbladder adenomas and used this finding to support the idea that adenomas are not the precursor of most invasive carcinomas (36). In contrast, studies from Japan have shown a higher frequency of K-ras gene mutation in gallbladder carcinomas and occurrence in precursor lesions. For example, Ajiki et al. (15) found K-ras gene mutations in $73 \%$ of gallbladder dysplasias and $59 \%$ of invasive carcinomas. The presence of K-ras gene mutations does correlate with the anatomic finding of anomalous junction of the choledochopancreatic ducts (AJCPD) outside of the ampulla of Vater, which is more common in Japan. Hanada et al. (10) showed that the rate of K-ras mutation was higher in gallbladder carcinomas of patients with AJCPD than in gallbladder carcinomas of patients without AJCPD (50\% versus $6 \%, P<.05)$. Our study shows an intermediate rate of mutation in our cohort of $30 \%$. Two of our three metastatic carcinomas harbored $\mathrm{K}$-ras gene mutations; however, we demonstrated a mutation in one patient with pure flat carcinoma in situ, indicating 
that this genetic alteration may be an early event in some cases.

In summary, our results with p53, p16, and K-ras are consistent with those of previous studies in the literature that have shown a significant rate of alterations in these genes in gallbladder carcinoma. Loss of p16 expression and accumulation of p53 at high levels are the most common abnormalities associated with these carcinomas. Our study is the first to show Dpc4 protein loss in gallbladder carcinoma. We also show that loss of pRB expression is rare in non-small cell gallbladder carcinoma but is common in small cell carcinoma of the gallbladder. Indeed, the p16/pRB pathway was inactivated in all six small cell carcinomas studied. Perhaps most important, using immunohistochemistry, we were able to localize all of these alterations to the stage of carcinoma in situ. Indeed, of 15 invasive carcinomas associated with an evaluable in situ component, there was complete concordance between the results in 13 cases. Along these lines, one case of pure in situ carcinoma in our study contained three distinct alterations: p53 accumulation, p16 loss, and $\mathrm{K}-$ ras gene mutation.

Hence, carcinoma in situ of the gallbladder, although clinically occult, is a genetically advanced lesion. These results suggest that patients with pure carcinoma in situ of the gallbladder should receive careful clinical follow-up, particularly if the status of the cystic duct margin is unclear. At the same time, these results highlight our ignorance of mechanisms and markers of progression in this lethal neoplasm.

\section{REFERENCES}

1. Albores-Saavedra J, Henson DE, Klimstra DS. Tumors of the gallbladder, extrahepatic bile ducts, and ampulla of Vater. Atlas of tumor pathology. 3rd series. Fascicle 27. Washington, D.C.: Armed Forces Institute of Pathology; 2000.

2. Levin B. Gallbladder carcinoma. Ann Oncol 1999;10:S12930 .

3. Henson DE, Albores-Saavedra J, Corle D. Carcinoma of the gallbladder. Histologic types, stage of disease, grade, and survival rates. Cancer 1992;70:1493-7.

4. Nugent KP, Spigelman AD, Talbot IC, Phillips RKS. Gallbladder dysplasia in patients with familial adenomatous polyposis. Br J Surg 1994;81:291-2.

5. Chang HJ, Kim SW, Kim Y-T, Kim WH. Loss of heterozygosity in dysplasia and carcinoma of the gallbladder. Mod Pathol 1999;12:763-9.

6. Wistuba II, Albores-Saavedra J. Genetic abnormalities involved in the pathogenesis of gallbladder carcinoma. J Hepatobiliary Pancreatic Surg 1999;6:237-44.

7. Wistuba II, Sugio K, Hung J, Kishimto Y, et al. Allele-specific mutations involved in the pathogenesis of endemic gallbladder carcinoma in Chile. Cancer Res 1995;55:2511-5.

8. Wistuba II, Tang M, Maitra A, et al. Genome-wide allelotyping analysis reveals multiple sites of allelic loss in gallbladder carcinoma. Cancer Res 2001;61:3795-800.

9. Gorunova L, Parada LA, Limon J, et al. Nonrandom chromosomal aberrations and cytogenetic heterogeneity in gallblad- der carcinomas. Genes Chromosomes Cancer 1999;26:31221.

10. Hanada K, Itoh M, Fujii K, Tsuchida A, Ooishi H, Kajiyama G. $\mathrm{K}$-ras and p53 mutations in stage 1 gallbladder carcinoma with an anomalous junction of the pancreaticobiliary duct. Cancer 1996;77:452-8.

11. Wistuba II, Gadzar AF, Roa I, Albores-Saavedra J. p53 protein expression in gallbladder carcinoma and its precursor lesions. An immunohistochemical study. Hum Pathol 1996;27: 360-5.

12. Yoshida S, Todoroki $\mathrm{T}$, Ichikawa $\mathrm{Y}$, et al. Mutations of $p 16^{\text {Ink4 }} / C D K N 2$ and $p 15^{\text {Ink4B }} / M S T 2$ genes in biliary tract cancers. Cancer Res 1995;55:2756-60.

13. Kim Y-T, Kim J, Jang YH, et al. Genetic alterations in gallbladder adenoma, dysplasia, and carcinoma. Cancer Lett 2001;169:59-68.

14. Kim SW, Her K-H, Jang J-Y, Kim W-H, Kim Y-T, Park Y-H. $\mathrm{K}$-ras oncogene mutation in cancer and precancerous lesions of the gallbladder. J Surg Oncol 2000;75:246-51.

15. Ajiki T, Fujimori T, Onoyama H, et al. K-ras gene mutation in gall bladder carcinomas and dysplasia. Gut 1996;38:426-9.

16. Watanabe M, Asaka M, Tanaka J, Kurosawa M, Kasai M, Miyazaki T. Point mutation of the K-ras gene codon 12 in biliary tract tumors. Gastroenterology 1994;107:1147-53.

17. Imai M, Hoshi T, Ogawa K. K-ras codon 12 mutations in biliary tract tumors detected by polymerase chain reaction denaturing gel electrophoresis. Cancer 1994;73:2727-33.

18. Itoi $\mathrm{T}$, Watanabe $\mathrm{H}$, Ajioka $\mathrm{Y}$, et al. APC, K-ras codon 12 mutations and p53 gene expression in carcinoma and adenoma of the gall-bladder suggest two genetic pathways in gall-bladder carcinogenesis. Pathol Int 1996;46:333-40.

19. Maitra A, Tascilar M, Hruban RH, Offerhaus GJ, AlboresSaavedra J. Small cell carcinoma of the gallbladder. A clinicopathologic, immunohistochemical, and molecular pathology study of 12 cases. Am J Surg Pathol 2001;25:595-601.

20. Fleming ID, Cooper JS, Henson DE, et al., editors. AJCC cancer staging handbook. Philadelphia, PA: LippincottRaven; 1997.

21. Baas IO, Mulder J-WR, Offerhaus GJA, Vogelstein B, Hamilton SR. An evaluation of six antibodies for immunohistochemistry of mutant p53 gene product in archival colorectal neoplasms. J Pathol 1994;172:5-12.

22. Wilentz RE, Su GH, Dai JL, et al. Immunohistochemical labeling for Dpc4 mirrors genetic status in pancreatic adenocarcinomas: a new marker of DPC4 inactivation. Am J Pathol 2000;156:37-43.

23. Geradts J, Kratzke RA, Crush-Stanton S, Wen SF, Lincoln CE. Wild-type and mutant retinoblastoma protein in paraffin sections. Mod Pathol 1996;9:339-47.

24. Geradts J, Hruban RH, Schutte M, Kern SE, Maynard R. Immunohistochemical p16 ${ }^{\text {INK4a }}$ analysis of archival tumors with deletion, hypermethylation, or mutation of the CDKN2/ MTS1 gene: a comparison of four commercial antibodies. Appl Immunohistochem Mol Morphol 2000;8:71-9.

25. Maitra A, Roberts H, Weinberg AG, Geradts J. Loss of p16 ${ }^{\text {INK4a }}$ expression correlates with decreased survival in pediatric osteosarcomas. Int J Cancer 2001;95:34-8.

26. Wilentz RE, Geradts J, Maynard R, et al. Inactivation of p16 (INK4A) tumor-suppressor gene in pancreatic duct lesions: loss of intranuclear expression. Cancer Res 1998;58:4740-4.

27. Hruban RH, Sturm PDJ, Slebos RJC, et al. Can K-ras mutations be used to distinguish benign bile duct proliferations from metastases to the liver? A molecular analysis of 101 liver lesions from 93 patients. Am J Pathol 1997;151:943-9.

28. Argani P, Shaukat A, Kaushal M, et al. Differing rates of Dpc4 expression and of p53 overexpression among carcinomas of the proximal and distal bile ducts. Evidence for a biologic distinction. Cancer 2001;91:1322-41. 
29. Shi Y-Z, Hui A-M, Li X, Tayayama T, Makuuchi M. Overexpression of retinoblastoma protein predicts decreased survival and correlates with loss of $\mathrm{p} 16^{\mathrm{INK} 4}$ protein in gallbladder carcinomas. Clin Cancer Res 2000;6:4096-100.

30. Benedict WF, Lerner SP, Zhou J, Shen X, Tokunaga H, Czerniak B. Level of retinoblastoma protein expression correlates with p16 (MTS-1/INK4A/CDKN2) status in bladder cancer. Oncogene 1999;18:1197-203.

31. Sakaguchi M, Fujii Y, Hirabayashi H, et al. Inversely correlated expression of p16 and RB protein in non-small cell lung cancers: an immunohistochemical study. Int J Cancer 1996; 8:442-5.

32. Ueki K, Ono Y, Henson JW, Efird JY, von Deimling A, Louis D. CDKN2/p16 or RB alterations occur in the majority of glioblastomas and are inversely correlated. Cancer Res 1996;56: $150-3$.
33. Shimizu E, Coxon A, Otterson GA, et al. RB protein status and clinical correlation from 171 cell lines representing lung cancer, extrapulmonary small cell carcinoma, and mesothelioma. Oncogene 1994;9:2441-8.

34. Herrington CS, Graham D, Southern SA, Bramdev A, Chetty R. Loss of retinoblastoma protein expression is frequent in small cell carcinoma of the uterine cervix and is unrelated to HPV type. Hum Pathol 1999;30:906-10.

35. Takubu K, Nakamura K, Sawabe M, et al. Primary small cell undifferentiated carcinoma of the esophagus. Hum Pathol 1999;30:216-21.

36. Wistuba II, Miquel JF, Gadzar AF, Albores-Saavedra J. Gallbladder adenomas have molecular abnormalities different from those present in gallbladder carcinomas. Hum Pathol 1999;30:21-5.

\section{Book Review}

\section{Nuland SB: Lost in America: A Journey with My Father, 212 pp, New York, Alfred A. Knopf, 2003 (\$24.00).}

At the moment, Americans are intrigued with the childhood struggles of other people, especially if they are immigrants (or first generation products) from Ireland or holocaust-affected regions of Europe. In spite of all the family deformations, the narrators typically end up with successful careers and fulfilled lives. And good writers from the medical ranks enjoy a special regard within this genre because their readers assume an added and special dimension, that these authors understand the chemistry and physics that make people tick. Sherwin B. Nuland, M.D., an emeritus clinical professor of surgery at Yale University, has already published several successful socio-medical books, and his Lost in America is bound to find a wide audience.

This short book can be pleasantly consumed in a weekend. It is a completely factual account, to the extent that there is no declaration otherwise, even with regard to possible name changes for peripheral characters such as Nuland's girlfriends. It reads like a novel in terms of gripping opening, tension, and skillful timing in the release of information, all presented in a smooth narrative style. Notwithstanding the title, the discourse is primarily autobiographical. His father, Meyer Nudelman, was a Russian Jew who arrived in 1907, on his own, and was never assimilated in terms of American culture or even language. Sherwin and his older brother Harvey officially changed the spelling of their surname while the author was in high school. After the premature death of their mother, the boys were nurtured by a maternal aunt, influenced by their maternal grandmother, embarrassed and needled by their father, all living in the same Bronx apartment. The interactions are at times novel, pitiful, solemn, wrenching, and even humorous, but never boring. The climacteric of Meyer's illness is expertly rendered.

Many of us would have been interested in some family portraits, but there is no illustration except for the unidentified, partial figures on the dust-cover, presumably Sherwin and Meyer. There are some troublesome paradoxes with regard to medical education and practice. For instance, Nuland dismisses the basic sciences (biochemistry in particular) as being of minor consequence to a medical education. He thus joins the throng of naive freshman, but it does not sit well with his more mature mantra about being totally prepared to understand the patient, at all levels.

Dr. Nuland tells us that he was driven to write this book by an attempt to evaluate the relationship with his departed father. He elects not to analyze the overall thesis, 'I will never know the cost of being Meyer's son. ' We are left to reach our own conclusion, and that is part of the charm of his contribution.

\section{Wilfred Niels Arnold \\ University of Kansas Medical Center \\ Kansas City, Kansas}

